\title{
Does Kinesiology Taping Improve Muscle Strength and Function in Knee Osteoarthritis? A Single-Blind, Randomized and Controlled Study
}

\author{
Halil ÖĞÜT@, Hayal GÜLER@, Mustafa Turgut YILDIZGÖREN@D, \\ Onur VELİGĞLU (iD, Ayșe Dicle TURHANOĞLU
}

Department of Physical Medicine and Rehabilitation, Hatay Mustafa Kemal University, Tayfur Ata Sökmen Faculty of Medicine, Hatay, Turkey

\begin{abstract}
Objectives: This study aims to evaluate the efficacy of kinesiology taping (KT) on pain, movement restriction, walking speed, daily living activities, and isokinetic muscle performance in female patients with knee osteoarthritis (OA).

Patients and methods: The study included 61 female patients (mean age $53.5 \pm 3.5$ years; range 50 to 60 years) who were admitted to Physical Medicine and Rehabilitation Outpatient Clinic with complaints of mechanical knee pain. Knee OA was diagnosed according to the clinical/ radiological criteria of the American College of Rheumatology and patients with Kellgren-Lawrence grade 2 and 3 were included. Patients were randomly divided into two groups. Both groups received transcutaneous electrical nerve stimulation for 30 minutes, hot pack for 30 minutes, and therapeutic ultrasound for 10 minutes in a day for three weeks (five days in a week). Also, one group was treated with $K T$ (KT group, $n=31$ ) while the other group was treated with sham-KT (sham-KT group, $n=30$ ) one time a week for three weeks. A home program of around the knee strengthening exercises was recommended for all patients. All patients were evaluated with Visual Analog Scale (VAS), Western Ontario and McMaster Osteoarthritis Index (WOMAC) values, goniometric measurement of active knee range of motion, 50-meter walking distance, and isokinetic knee extensor muscle peak torque measurements before treatment, at the end of treatment, and at one month and three months after treatment.

Results: There was a significant improvement in after treatment and first month VAS values in the KT group compared to the sham-KT group $(p<0.05)$. In the KT group, the WOMAC pain and WOMAC total scores decreased significantly after treatment compared to the sham-KT group $(p<0.05)$. VAS values were significantly decreased after treatment in both groups $(p<0.05)$. In both groups; WOMAC pain, stiffness, physical function, and total values decreased significantly after treatment $(p<0.05)$. In both groups, isokinetic quadriceps peak torque measurements were increased after treatment $(p<0.05)$.
\end{abstract}

Conclusion: The application of KT to females with knee OA appears to be a method that may be effective on pain and functional capacity.

Keywords: Isokinetic muscle performance; kinesiology taping; knee osteoarthritis; Western Ontario and McMaster Osteoarthritis Index.

Osteoarthritis (OA) is a frequently seen degenerative disease, having increasing prevalence with increasing age, more often seen in females, and characterized by subchondral bone sclerosis and synovial membrane changes, leading to serious morbidity, primarily joint cartilage degeneration. ${ }^{1}$ Symptomatically, the joint mostly involved is the knee and this is known to cause greater loss of ability than other joint involvements. With pain and loss of strength in the muscles around the knee, knee OA has a negative effect on daily living activities such as going up and down stairs, walking, standing, and balancing, and increases the dependence of the patient. ${ }^{2}$ There are a great number of options to manage symptoms. Modification of daily living activities, weight loss, exercise, physical therapy, electrotherapy and taping, paracetamol, nonsteroidal antiinflammatory drugs, opioids, and injection 
therapies alleviate symptoms in most patients with mild-moderate knee OA. ${ }^{3}$

Kinesiology taping (KT) with elastic adhesive material has emerged as an interesting method that can be applied virtually in any musculoskeletal injury. The effect of KT is thought to increase local blood circulation by increasing the cutaneous and subcutaneous interstitial area, reduce inflammation and pain, provide neuromuscular re-education, prevent injury and accelerate healing. ${ }^{4,5}$ Although the immediate effects of KT are being investigated in the treatment of knee $\mathrm{OA}$, there are limited data on its efficacy or the evaluation of application methods. ${ }^{6}$

Therefore, in this study, we aimed to evaluate the efficacy of KT on pain, movement restriction, walking speed, daily living activities, and isokinetic muscle performance in female patients with knee OA.

\section{PATIENTS AND METHODS}

The study included 61 female patients (mean age $53.5 \pm 3.5$ years; range 50 to 60 years) admitted to the Physical Medicine and Rehabilitation Clinic of Hatay Mustafa Kemal University, Tayfur Ata Sökmen Faculty of Medicine between January 2016 and September 2016, and diagnosed with knee OA according to American College of Rheumatology diagnostic criteria ${ }^{7}$ and with Kellgren-Lawrence (K-L) grade 2 or 3 (Figure 1). The study protocol was approved by the Hatay
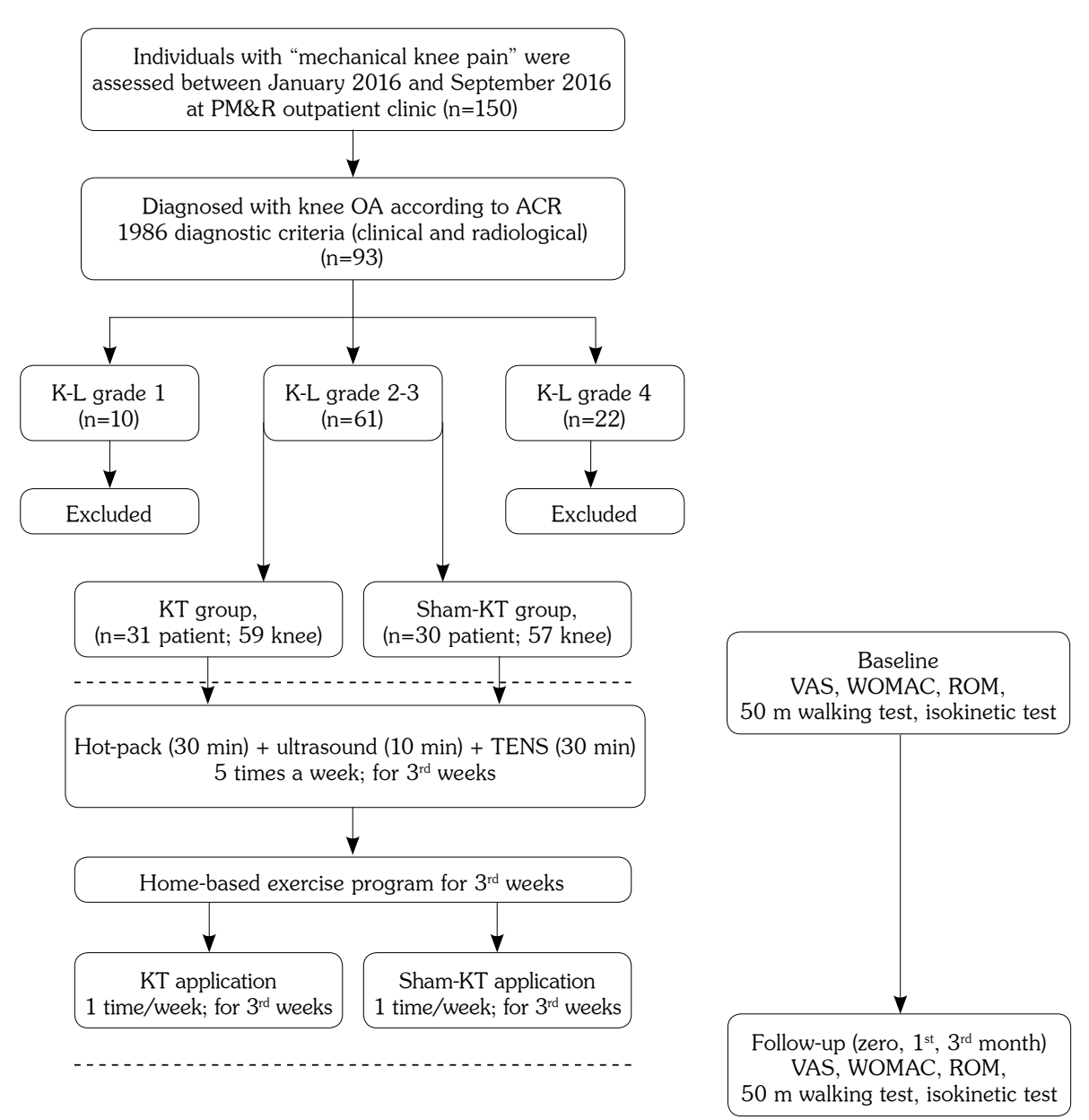

Figure 1. Flow chart of study design. PM\&R: Physical Medicine and Rehabilitation; OA: Osteoarthritis; ACR: American College of Rheumatology; K-L: Kellgren-Lawrence; KT: Kinesiology taping; TENS: Transcutaneous electrical nerve stimulation; VAS: Visual Analog Scale; WOMAC: Western Ontario and McMaster Osteoarthritis Index; ROM: Range of motion. 


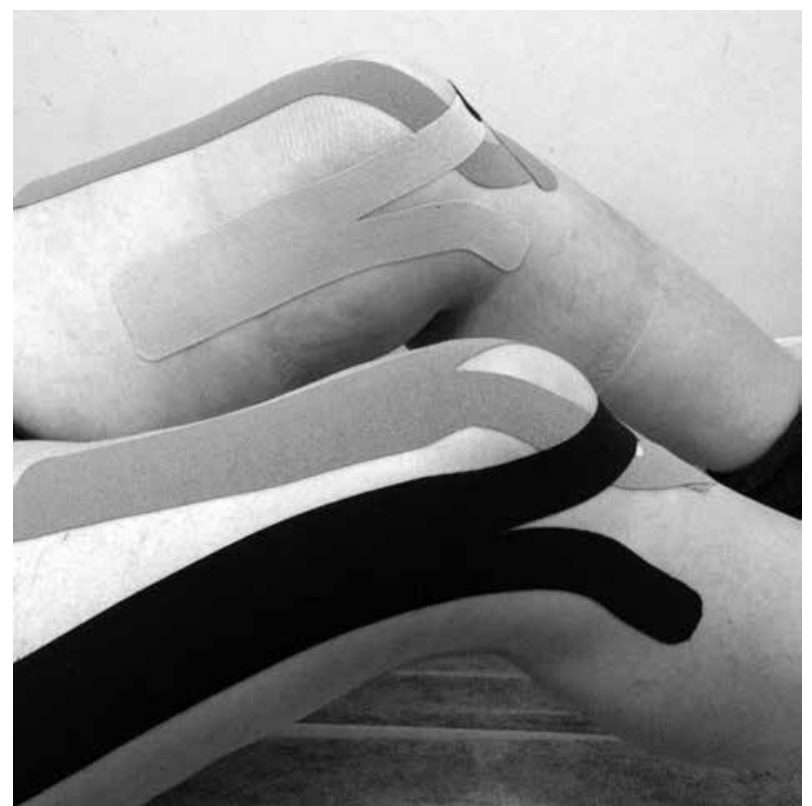

Figure 2. Kinesiology taping application for knee extensors.

Mustafa Kemal University, Tayfur Ata Sökmen Faculty of Medicine Ethics Committee (no. 17, dated 01.03.2016). A written informed consent was obtained from each patient. The study was conducted in accordance with the principles of the Declaration of Helsinki.

Patients were randomly separated into two groups. All patients in both groups were applied with a hot pack for 30 minutes, transcutaneous electrical nerve stimulation (TENS) for 30 minutes $(100 \mathrm{~Hz}$ frequency and 60 milliseconds pulse duration), ultrasound therapy for 10 minutes (pulsed $1: 1,1 \mathrm{MHz}$ frequency, and $1.5 \mathrm{~W} / \mathrm{cm}^{2}$ intensity) and an isometric exercise program around the knee for a total of 15 sessions over a period of three weeks. In one group, patients received KT (KT group, $\mathrm{n}=31$ ) to the quadriceps muscle once a week for three weeks (Figure 2). The other group received sham-KT applied without tension (sham-KT group, $\mathrm{n}=30$ ) with 10 centimeters of KT administered transversely over the quadriceps muscle (Figure 3).

Patients were excluded if they had any history of lower extremity surgery, K-L grade 1 or 4, received intraarticular knee joint injections within the last six months, any diagnosis of musculoskeletal disease other than OA, evident sensory or strength loss in the lower extremity,

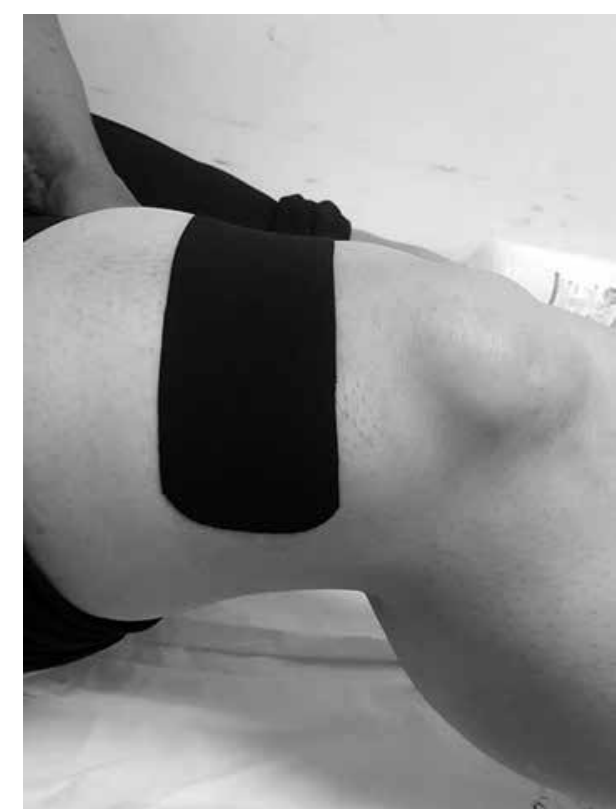

Figure 3. Sham-kinesiology taping application.

any cognitive impairment that would prevent participation in treatment, open wound or skin lesions in the area where KT was to be applied, or any known skin allergies.

All patients' age, height, weight, occupation, level of education, duration of symptoms, and K-L grade were recorded. Visual Analog Scale (VAS) and Western Ontario and McMaster Osteoarthritis Index (WOMAC) values were recorded for all patients before treatment, at the end of treatment, and at first and third months after treatment. The active knee joint range of movement (goniometric measurement), 50-meter walking time, and isokinetic knee extensor muscle peak torque measurements were also evaluated for all patients at baseline, at the end of treatment, and at first and third months after treatment.

In the measurement of isokinetic muscle strength, the Humac $^{\circledR} \quad$ Norm $^{\mathrm{TM}}$ isokinetic dynamometer (Computer Sports Medicine Inc., Stoughton/Massachusetts, USA) was used. The performance of the extensor muscles of the affected knee was evaluated with isokinetic tests in all patients in both groups before treatment, at the end of treatment, and at first and third months after treatment. The isokinetic test protocol was applied with five repetitions at an angular rate of $60 \%$ second, 15 seconds rest, and 
Table 1. Demographic, clinical, radiographic, and isokinetic features of patients

\begin{tabular}{|c|c|c|c|c|c|c|c|}
\hline & \multicolumn{3}{|c|}{ Kinesiology taping $(\mathrm{n}=31)$} & \multicolumn{3}{|c|}{ Sham-Kinesiology taping $(n=30)$} & \multirow[b]{2}{*}{$p$} \\
\hline & $\mathrm{n}$ & $\%$ & Mean \pm SD & $\mathrm{n}$ & $\%$ & Mean \pm SD & \\
\hline Age (year) & & & $53.8 \pm 3.5$ & & & $53.1 \pm 3.6$ & 0.954 \\
\hline Weight (kg) & & & $84.0 \pm 5.4$ & & & $83 . \pm 6.7$ & 0.116 \\
\hline Height $(\mathrm{cm})$ & & & $158.1 \pm 4.6$ & & & $158.1 \pm 4.5$ & 0.901 \\
\hline Body Mass Index $\left(\mathrm{kg} / \mathrm{m}^{2}\right)$ & & & $33.6 \pm 2.3$ & & & $33.2 \pm 2.8$ & 0.389 \\
\hline Symptom duration (mo) & & & $23.1 \pm 22$ & & & $29.5 \pm 23$ & 0.257 \\
\hline Affected side & & & & & & & 0.876 \\
\hline Right & 30 & 96.7 & & 29 & 96.6 & & \\
\hline Left & 29 & 93.5 & & 28 & 93.3 & & \\
\hline K-L grade & & & & & & & 0.131 \\
\hline Grade 2 & 40 & 67.7 & & 36 & 63.2 & & \\
\hline Grade 3 & 19 & 32.3 & & 21 & 36.8 & & \\
\hline \multicolumn{8}{|l|}{ Baseline evaluations } \\
\hline Visual Analog Scale-resting & & & $5.1 \pm 0.8$ & & & $5.1 \pm 0.7$ & 1.000 \\
\hline Range of motion & & & $127.0 \pm 2.0$ & & & $126.7 \pm 1.9$ & 0.622 \\
\hline $50 \mathrm{~m}$ walking test & & & $35.5 \pm 2.5$ & & & $35.6 \pm 2.4$ & 0.983 \\
\hline \multicolumn{8}{|l|}{ WOMAC scores } \\
\hline Pain & & & $10.4 \pm 1.5$ & & & $10.4 \pm 1.4$ & 0.935 \\
\hline Stiffness & & & $2.5 \pm 0.5$ & & & $2.6 \pm 0.6$ & 0.415 \\
\hline Physical function & & & $31.5 \pm 4.5$ & & & $31.8 \pm 4.2$ & 0.717 \\
\hline Total & & & $44.5 \pm 5.8$ & & & $44.9 \pm 4.8$ & 0.649 \\
\hline \multicolumn{8}{|l|}{ Isokinetic evaluation, $\mathrm{PT}(\mathrm{Nm})$} \\
\hline $60 \% \sec \mathrm{AV}$ & & & $51.4 \pm 6.4$ & & & $51.2 \pm 6.5$ & 0.902 \\
\hline $180^{\circ} / \mathrm{sec}$ AV & & & $41.0 \pm \pm 6.1$ & & & $40.6 \pm 6.5$ & 0.834 \\
\hline
\end{tabular}

then 15 repetitions at $180 \%$ second. Before the evaluation, three submaximal repetitions were applied for patient adaptation.

For KT, vastus medialis, vastus lateralis, and rectus femoris heads were selected. In all three muscles, the muscle stimulation technique was applied according to the method described by Kenzo Kase. ${ }^{4}$ The tapes (Kinopain Sports Tape ${ }^{\circledR}$ ) were cut to size specific to the individual's height and prepared in the form of "Y band". As the

Table 2. Baseline, after treatment, and first and third month follow-up results of clinical measurements

\begin{tabular}{|c|c|c|c|c|c|}
\hline & \multicolumn{2}{|c|}{$\mathrm{KT}(\mathrm{n}=31)$} & \multicolumn{2}{|c|}{ Sham-KT $(\mathrm{n}=30)$} & \multirow[b]{2}{*}{$p$} \\
\hline & Mean \pm SD & $\% \Delta$ & Mean \pm SD & $\% \Delta$ & \\
\hline \multicolumn{6}{|l|}{ Visual Analog Scale resting } \\
\hline Before treatment & $5.1 \pm 0.8$ & & $5.1 \pm 0.7$ & & \\
\hline After treatment (zero month) & $1.7 \pm 0.6$ & -66.6 & $2.1 \pm 0.3$ & -58.8 & 0.003 \\
\hline After treatment ( $1^{\text {st }}$ month) & $1.4 \pm 0.6$ & -72.5 & $1.8 \pm 0.8$ & -64.7 & 0.011 \\
\hline After treatment ( $3^{\text {rd }}$ month) & $1.8 \pm 0.3$ & -64.7 & $1.8 \pm 0.3$ & -64.7 & 0.820 \\
\hline p values*** & \multicolumn{2}{|c|}{$<0.001 \dagger$} & \multicolumn{2}{|c|}{$0.001 \neq$} & \\
\hline \multicolumn{6}{|l|}{$50 \mathrm{~m}$ walking test (sec) } \\
\hline Before treatment & $35.5 \pm 2.5$ & & $35.6 \pm 2.4$ & & \\
\hline After treatment (zero month) & $33.1 \pm 2.2$ & -7.2 & $33.1 \pm 2.5$ & -7.0 & 0.919 \\
\hline After treatment ( $1^{\text {st }}$ month) & $31.5 \pm 2.3$ & -11.2 & $31.6 \pm 2.2$ & -11.2 & 0.948 \\
\hline After treatment ( $3^{\text {rd }}$ month) & $31.1 \pm 1.8$ & -12.3 & $31.3 \pm 1.7$ & -12.0 & 0.747 \\
\hline p values*** & \multicolumn{2}{|c|}{$0.001 \dagger$} & \multicolumn{2}{|c|}{$<0.001 \ddagger$} & \\
\hline \multicolumn{6}{|l|}{ Range of motion (degree) } \\
\hline Before treatment & $127.0 \pm 2.0$ & & $126.7 \pm 1.9$ & & \\
\hline After treatment (zero month) & $132.4 \pm 2.1$ & 4.2 & $132.0 \pm 2.1$ & 4.1 & 0.292 \\
\hline After treatment ( $1^{\text {st }}$ month) & $133.1 \pm 1.9$ & 4.8 & $132.6 \pm 1.8$ & 4.6 & 0.315 \\
\hline After treatment ( $3^{\text {rd }}$ month) & $133.1 \pm 2.3$ & 4.8 & $132.6 \pm 2.3$ & 4.6 & 0.435 \\
\hline$p$ values** & \multicolumn{2}{|c|}{$0.001 \dagger$} & \multicolumn{2}{|c|}{$<0.05 \neq$} & \\
\hline
\end{tabular}


aim was muscle stimulation, the application was performed from the muscle origin towards the insertion. For the rectus femoris muscle, with the hip in a neutral position, the tape was applied from approximately $10 \mathrm{~cm}$ below the spina iliaca anterior superior towards the upper edge of the patella and after applying without stretching, by bringing the knee into flexion, the tape was wound around the patella and attached to the lower edge.

For the vastus lateralis muscle, with the hip in a neutral position, after applying the tape without stretching from the trochanter major towards the distal thigh, one end of the tape was taken to the fibula head and the other end was attached to the lower edge of the patella by passing lateral to the patella (with full stretching). For the vastus medialis muscle, with the hip in a neutral position, after attaching the tape from the distal third of the thigh as far as the patella medial without stretching, the knee was taken into flexion and one end of the tape was taken towards the medial tibia and the other was passed around the medial patella (with full stretching) and the tape was attached to the lower edge of the patella. The tapes were applied throughout three weeks and were changed at intervals of three to seven days.

Randomization was performed by generating random numbers as the intervention group and control group. All measurements and KT applications were performed by the same physician, who was blinded to the groups' assignment at the beginning and the end of the study.

\section{Statistical analysis}

Statistical analysis was conducted using IBM SPSS for Windows, version 21.0 software (IBM Corp., Armonk, NY, USA). Descriptive statistical results were shown as mean \pm standard deviation for continuous data, or number ( $n$ ) and percentage (\%) for categorical data. Baseline characteristics were compared with the Chisquare (Yates correction test) and Student's t-tests where appropriate. Baseline and after treatment

\begin{tabular}{|c|c|c|c|c|c|}
\hline & \multicolumn{2}{|c|}{$\mathrm{KT}(\mathrm{n}=31)$} & \multicolumn{2}{|c|}{ Sham-KT $(n=30)$} & \multirow[b]{2}{*}{$p$} \\
\hline & Mean \pm SD & $\% \Delta$ & Mean \pm SD & $\% \Delta$ & \\
\hline \multicolumn{6}{|l|}{ WOMAC pain } \\
\hline Before treatment & $10.4 \pm 1.5$ & & $10.4 \pm 1.4$ & & \\
\hline After treatment (zero month) & $4.9 \pm 0.6$ & -52.8 & $5.4 \pm 0.6$ & -48.0 & 0.011 \\
\hline After treatment ( $1^{\text {st }}$ month) & $4.0 \pm 0.8$ & -61.5 & $4.1 \pm 0.5$ & -60.5 & 0.635 \\
\hline After treatment ( $3^{\text {rd }}$ month) & $4.0 \pm 0.9$ & -61.5 & $4.0 \pm 0.7$ & -61.5 & 0.900 \\
\hline$p$ values** & \multicolumn{2}{|c|}{$<0.05 \dagger$} & \multicolumn{2}{|c|}{$0.001 \neq$} & \\
\hline \multicolumn{6}{|l|}{ WOMAC stiffness } \\
\hline Before treatment & $2.5 \pm 0.5$ & & $2.6 \pm 0.6$ & & \\
\hline After treatment (zero month) & $1.3 \pm 0.6$ & -48.0 & $1.4 \pm 0.5$ & -46.1 & 0.637 \\
\hline After treatment ( $1^{\text {st }}$ month) & $1.2 \pm 0.8$ & -52.0 & $1.2 \pm 0.8$ & -53.8 & 0.988 \\
\hline After treatment ( $3^{\text {rd }}$ month) & $1.4 \pm 0.5$ & -44.0 & $1.6 \pm 0.5$ & -38.4 & 0.317 \\
\hline$p$ values** & \multicolumn{2}{|c|}{$0.001 \dagger$} & \multicolumn{2}{|c|}{$0.001 \neq$} & \\
\hline \multicolumn{6}{|l|}{ WOMAC physical function } \\
\hline Before treatment & $31.5 \pm 4.5$ & & $31.8 \pm 4.2$ & & \\
\hline After treatment (zero month) & $21.4 \pm 4.4$ & -32.0 & $23.9 \pm 4.5$ & -24.8 & 0.028 \\
\hline After treatment ( $1^{\text {st }}$ month) & $16.1 \pm 4.2$ & -48.8 & $16.6 \pm 4.1$ & -47.7 & 0.612 \\
\hline After treatment ( $3^{\text {rd }}$ month) & $15.4 \pm 4.0$ & -51.1 & $15.9 \pm 3.9$ & -50.0 & 0.582 \\
\hline$p$ values** & \multicolumn{2}{|c|}{$0.001 \dagger$} & \multicolumn{2}{|c|}{$0.001 \neq$} & \\
\hline \multicolumn{6}{|l|}{ WOMAC total } \\
\hline Before treatment & $44.5 \pm 5.8$ & & $44.9 \pm 4.8$ & & \\
\hline After treatment (zero month) & $27.7 \pm 4.8$ & -37.7 & $30.8 \pm 4.6$ & -31.4 & 0.015 \\
\hline After treatment ( $1^{\text {st }}$ month) & $21.4 \pm 4.7$ & -51.9 & $21.9 \pm 4.1$ & -51.2 & 0.623 \\
\hline After treatment ( $3^{\text {rd }}$ month) & $21.0 \pm 4.5$ & -52.8 & $21.5 \pm 4.2$ & -52.1 & 0.649 \\
\hline$p$ values*** & \multicolumn{2}{|c|}{$<0.001 \dagger$} & \multicolumn{2}{|c|}{$0.001 \neq$} & \\
\hline
\end{tabular}




\begin{tabular}{|c|c|c|c|c|c|}
\hline \multirow[b]{2}{*}{ Extensor peak torque } & \multicolumn{2}{|c|}{$\mathrm{KT}(\mathrm{n}=31)$} & \multicolumn{2}{|c|}{ Sham-KT $(n=30)$} & \multirow[b]{2}{*}{$p$} \\
\hline & Mean \pm SD & $\% \Delta$ & Mean \pm SD & $\% \Delta$ & \\
\hline \multicolumn{6}{|l|}{$60^{\circ} / \mathrm{sec}$ AV $(\mathrm{Nm})$} \\
\hline Before treatment & $51.4 \pm 6.4$ & & $51.2 \pm 6.5$ & & \\
\hline After treatment (zero month) & $64.1 \pm 6.3$ & 24.7 & $62.0 \pm 6.3$ & 21.0 & 0.219 \\
\hline After treatment ( $1^{\text {st }}$ month $)$ & $60.0 \pm 5.8$ & 16.7 & $59.7 \pm 6.1$ & 16.1 & 0.851 \\
\hline $\begin{array}{l}\text { After treatment ( } 3^{\text {rd }} \text { month) } \\
\text { p values }{ }^{* *}\end{array}$ & \multicolumn{2}{|c|}{$0.001 \dagger$} & \multicolumn{2}{|c|}{$0.001 \neq$} & 0.644 \\
\hline \multicolumn{6}{|l|}{$180^{\circ} / \mathrm{sec} \mathrm{AV}(\mathrm{Nm})$} \\
\hline Before treatment & $41.0 \pm 6.1$ & & $40.6 \pm 6.5$ & & \\
\hline After treatment (zero month) & $53.0 \pm 6.8$ & 29.2 & $50.8 \pm 6.7$ & 25.1 & 0.222 \\
\hline After treatment ( $1^{\text {st }}$ month) & $49.1 \pm 6.8$ & 19.7 & $48.7 \pm 6.6$ & 19.9 & 0.817 \\
\hline After treatment ( $3^{\text {rd }}$ month) & $45.1 \pm 6.0$ & 10.0 & $44.8 \pm 6.5$ & 10.3 & 0.896 \\
\hline$p$ values ** & \multicolumn{2}{|c|}{$0.001 \dagger$} & \multicolumn{2}{|c|}{$<0.001 \neq$} & \\
\hline
\end{tabular}

results were evaluated using paired sample t-tests. In the comparison of repeated measurements within a group, analysis of variance and posthoc Bonferroni correction were used. A value of $p<0.05$ was considered statistically significant.

\section{RESULTS}

No significant differences were determined between the groups in respect of age, Body Mass Index, symptom duration, K-L grade, VAS pain, knee range of motion (ROM), WOMAC, 50 -meter walking test, or isokinetic test values ( $p>0.05$ for all). Demographic, radiological, and baseline clinical and isokinetic test values were shown in Table 1.

Regarding VAS pain scores, knee ROM, and 50-meter walking test time values, significant differences were determined between baseline values and values at zero, one, and three months after treatment (all $\mathrm{p}<0.05$ ) within the groups (Table 2). When the WOMAC pain, stiffness, physical function, and total scores were evaluated, significant improvements were determined in the zero, one, and three-month values compared to baseline values within the groups (Table 3). Regarding isokinetic assessments, significant differences were determined in both groups in the zero, one, and three-month values when compared to baseline values (Table 4).

When the change levels (\%) of the VAS scores were compared between the groups, a significant improvement was observed in the KT group compared to sham-KT group just after the treatment $(p=0.003)$, and at first month $(p=0.011)$ evaluations. When the change levels (\%) of the WOMAC pain and WOMAC physical function scores were compared between the groups, a significant improvement was observed in the KT group compared to sham-KT group just after the treatment ( $p=0.011$ and $p=0.028$, respectively) (Tables 2 and 3).

\section{DISCUSSION}

In this study, the effects of the application of $\mathrm{KT}$ to the quadriceps muscle in addition to hotpack, TENS, and ultrasound treatment on pain, functional capacity, and muscle strength were examined in female patients with a diagnosis of knee OA. In KT and sham-KT groups, there were significant improvements in VAS scores. The VAS scores of the KT group were lower at zero, one, and three months after treatment. Significant improvements were observed in the WOMAC pain, physical function, and total scores in the KT group at zero month after treatment. No significant difference was found between the KT group and the sham-KT group in respect of quadriceps peak torque values.

The frequency of $\mathrm{OA}$, which the most commonly seen joint disease, increases with age. ${ }^{8}$ Clinically, there may be pain, stiffness, restricted movement, crepitation, functional failure, and loss 
of daily living activities. There may be a reduction in quadriceps muscle strength which develops secondary to knee pain. ${ }^{9,10} \mathrm{KT}$ has been reported to provide muscle facilitation and to have an analgesic effect. ${ }^{4,5}$

In the current study, the knee pain of patients was evaluated with VAS, which showed that the before treatment VAS values were similar in both groups ( $p>0.05$ ). While a statistically significant difference was determined between the KT group and the sham-KT group in the VAS values immediately after treatment and at one month $(p<0.05)$, there was no significant difference between the three-month values $(p>0.05)$. In the comparisons within the groups, there was a statistically significant difference in the one and three-month after treatment values compared to the before treatment values $(p<0.05)$. The VAS values of both groups were determined to be lower after treatment. Castrogiovanni et al. ${ }^{11}$ separated 66 patients with knee OA into three groups and applied exercises only to the first group, exercises and KT to the second group, and exercises and non-stretched KT to the third group. When the VAS values were examined at 15 days and three months, while a reduction was determined in all three groups, the change in the KT group was determined to be significant. In a study by Cho et al. ${ }^{6}$ of 46 knee OA patients, a statistically significant decrease was determined in KT group's walking pain values in the measurements taken after the application of KT and placebo KT. However, Cho et al. ${ }^{6}$ performed a single application in their study; thus, the longterm effects of KT application remained unclear. Moreover, Kuru et al. ${ }^{12}$ compared the efficacy of $\mathrm{KT}$ and electrical stimulation in patients diagnosed with patellofemoral pain syndrome. While a reduction was determined in the VAS values of both groups, no significant difference was found between the groups. However, assessments were performed only twice, at baseline and sixthweek. Therefore, the persistence of the effect of treatment was not clear. In the current study, it was determined that although the application of $\mathrm{KT}$ could reduce pain for up to one month, the effect was not long-lasting.

Kola $^{13}$ examined the effect of KT application on walking speed in OA. Measurements of 10-meter walking speed were taken before treatment and on the first and third days, and it was concluded that the application of $\mathrm{KT}$ increased walking speed. Ekiz et al. ${ }^{14}$ applied KT to the quadriceps muscle of stroke patients and determined no significant increase in walking speed after treatment compared to the control group. Furthermore, in a study of 11 basketball players, Wohltman ${ }^{15}$ determined a positive effect of KT treatment on walking speed. In the current study, no significant difference was determined between the groups in respect of the 50-meter walking speed $(p>0.05)$. In the comparisons within the groups, while an increase in walking speed was determined after treatment in both groups $(p<0.05)$, no significant difference was determined between the first and third month values in either group ( $p>0.05)$.

Cho et al. ${ }^{6}$ compared KT treatment and placebo $\mathrm{KT}$ in patients with knee OA and determined a significant increase in the goniometric measurement values of active joint range of movement of the patients. In a study by Akinbo and Ojetunde ${ }^{16}$ of 60 patients with acute or chronic knee OA, the effect of KT application on joint range of movement was evaluated. The application of KT was found to be more effective on joint range of movement in those with acute knee pain compared to those with chronic knee pain. Despite the conflicting information in the literature, in the current study, there was no statistically significant difference between the groups when the joint range of movement values were compared before treatment, after treatment, and at one and three months ( $p>0.05)$. In the comparisons within the groups, a statistically significant increase was determined in both groups in the after treatment and one and three-month values compared to the before treatment values $(p<0.05)$.

There was no difference between the groups in respect of the before treatment WOMAC pain, stiffness, physical function, and total scores $(p>0.05)$. While a statistically significant difference was determined in the after treatment WOMAC pain, physical function, and total scores in the KT group ( $>>0.05)$, there was no difference between the groups in the first and third month values ( $p>0.05)$. In a study by Dhanakotti et al. ${ }^{17}$ of 30 knee OA patients, a significant reduction was determined in the WOMAC values in the group applied with $\mathrm{KT}$ compared to the control group in the before treatment and three-week after 
treatment evaluations. Kaya et al. ${ }^{18}$ compared $\mathrm{KT}$ and placebo KT in 42 knee OA patients and demonstrated that the change in the WOMAC scores of the study group was more significant. These findings support the results of the current study. In the light of these results, it can be concluded that the positive effect on pain and physical function of the application of KT to knee OA patients lasted for a short period.

$\mathrm{Fu}$ et al. ${ }^{19}$ evaluated the effect of KT application on muscle strength in 14 healthy young athletes. No increase or decrease was determined in isokinetic muscle strength between the measurements taken pre-application, postapplication, and at 12 hours post-application. In a study by Vercelli et al., ${ }^{20} 36$ healthy volunteers were separated into three groups. KT was applied to the quadriceps femoris muscle with the stimulation technique in the first group, with the inhibition technique in the second group, and as placebo tape in the third group. No significant change was determined in isokinetic muscle strength in any of the three groups. Moreover, Kaya et al. ${ }^{18}$ compared KT and placebo KT applications in 42 knee OA patients and determined no difference between the groups in respect of muscle strength. In the current study, isokinetic evaluation was performed for the muscles around the knee and the before treatment peak torque values were found to be similar between the groups ( $p>0.05)$. In the after treatment measurements, no statistically significant difference was detected between the groups ( $p>0.05)$. Thus it was determined that the application of KT in this study did not create any significant difference in the quadriceps peak torque values. In the comparisons within the groups, the increase in the first and third month peak torque values could have been related to the knee strengthening exercises applied to the patients.

Our study has some limitations. The first is that no power analysis was applied before the study. Secondly, although all the OA patients were given home-based exercise program, they were not questioned as to whether they had performed the exercises regularly. Thirdly, severe and mild OA patients (K-L grade I and IV) were excluded in the study.

In conclusion, our results show that $\mathrm{KT}$ seems to have only sudden effects on pain and physical function, but not to have longterm effects in knee OA. The physical therapy modalities and exercises applied in the treatment of OA provided an improvement in patient symptoms and an increase in muscle strength. A combination of these treatments with KT applied to the quadriceps muscle may provide more effective improvement in pain and physical functions in the short-term. However, there is a need for further studies in respect of the effect of the application of KT on muscle strength in patients with knee OA. Nevertheless, KT applied to the quadriceps muscle seems to be an effective adjuvant therapy in the treatment of knee OA.

\section{Declaration of conflicting interests}

The authors declared no conflicts of interest with respect to the authorship and/or publication of this article.

\section{Funding}

The authors received no financial support for the research and/or authorship of this article.

\section{REFERENCES}

1. Kaya E, Kaplan C, Carli AB, Guzelkucuk U. Effects of Balneotherapy and physical therapy on sleep quality in patients with osteoarthritis aged 50 to 85 years. Arch Rheumatol 2016;31:1-5.

2. Slemenda C, Brandt KD, Heilman DK, Mazzuca S, Braunstein EM, Katz BP, et al. Quadriceps weakness and osteoarthritis of the knee. Ann Intern Med 1997; 127:97-104.

3. Basedow M, Runciman WB, March L, Esterman A. Australians with osteoarthritis; the use of and beliefs about complementary and alternative medicines. Complement Ther Clin Pract 2014;20:237-42.

4. Kase K, Wallis J, Kase T. Clinical therapeutic applications of the kinesio taping method. 2nd ed. Tokyo: Ken Ikai Co. Ltd.; 2003.

5. Kalichman L, Vered E, Volchek L. Relieving symptoms of meralgia paresthetica using Kinesio taping: a pilot study. Arch Phys Med Rehabil 2010;91:1137-9.

6. Cho HY, Kim EH, Kim J, Yoon YW. Kinesio taping improves pain, range of motion, and proprioception in older patients with knee osteoarthritis: a randomized controlled trial. Am J Phys Med Rehabil 2015;94:192-200.

7. Altman R, Asch E, Bloch D, Bole G, Borenstein $\mathrm{D}$, Brandt $\mathrm{K}$, et al. Development of criteria for the classification and reporting of osteoarthritis. Classification of osteoarthritis of the knee. Diagnostic 
and Therapeutic Criteria Committee of the American Rheumatism Association. Arthritis Rheum 1986;29:1039-49.

8. Pereira D, Peleteiro B, Araújo J, Branco J, Santos RA, Ramos E. The effect of osteoarthritis definition on prevalence and incidence estimates: a systematic review. Osteoarthritis Cartilage 2011;19:1270-85.

9. Hunter DJ, McDougall JJ, Keefe FJ. The symptoms of osteoarthritis and the genesis of pain. Med Clin North Am 2009;93:83-100.

10. Lewek MD, Rudolph KS, Snyder-Mackler L. Quadriceps femoris muscle weakness and activation failure in patients with symptomatic knee osteoarthritis. J Orthop Res 2004;22:110-5.

11. Castrogiovanni P, Di Giunta A, Guglielmino C, Roggio F, Romeo, D, Fidone F, et al. The effects of exercise and kinesio tape on physical limitations in patients with knee osteoarthritis. J Funct Morphol Kinesiol 2016;1:355-68.

12. Kuru T, Yalıman A, Dereli EE. Comparison of efficiency of Kinesio ${ }^{\circledR}$ taping and electrical stimulation in patients with patellofemoral pain syndrome. Acta Orthop Traumatol Turc 2012;46:385-92.

13. Kola I. Physiotherapy effects on gait speed in patients with knee osteoarthritis. J Int Academic Research Multidisciplinary 2016;4:38-44.

14. Ekiz T, Aslan MD, Özgirgin N. Effects of Kinesio Tape application to quadriceps muscles on isokinetic muscle strength, gait, and functional parameters in patients with stroke. J Rehabil Res Dev 2015;52:323-31.
15. Wohltman H. The Effects of Kinesio Tape on Sports Performance: Vertical Jump and Shuttle Run Performance in Women's College Basketball Players. Masters Theses/2374; Available at: http://thekeep. eiu.edu/theses/2374

16. Akinbo S, Ojetunde A. Comparison of the Effect of Kinesiotape on Pain and Joint Range of Motion in Patients with Knee Joint Osteoarthritis and Knee Sport Injury. Nigerian Medical Practitioner 2007;52:65-9.

17. Dhanakotti S, Samuel RK, Thakar M, Doshi S, Vadsola K. Effects of additional kinesiotaping over the conventional physiotherapy exercise on pain, quadriceps strength and knee functional disability in knee osteoarthritis participants: a randomized controlled study. IJHSR 2016;6:221-9.

18. Kaya Mutlu E, Mustafaoglu R, Birinci T, Razak Ozdincler A. Does Kinesio Taping of the Knee Improve Pain and Functionality in Patients with Knee Osteoarthritis?: A Randomized Controlled Clinical Trial. Am J Phys Med Rehabil 2017;96:25-33.

19. Fu TC, Wong AM, Pei YC, Wu KP, Chou SW, Lin YC. Effect of Kinesio taping on muscle strength in athletes-a pilot study. J Sci Med Sport 2008;11:198201.

20. Vercelli S, Sartorio F, Foti C, Colletto L, Virton D, Ronconi $\mathrm{G}$, et al. Immediate effects of kinesiotaping on quadriceps muscle strength: a single-blind, placebo-controlled crossover trial. Clin J Sport Med 2012;22:319-26. 